\title{
Covid-19 em uma Região Metropolitana: vulnerabilidade social e políticas públicas em contextos de desigualdades
}

\author{
Covid-19 in a Metropolitan Region: public polices and social \\ vulnerability within a context of inequality \\ Arthur Chioro', Karina Calife ${ }^{\mathbf{2}}$, Cláudia Renata dos Santos Barros ${ }^{\mathbf{3}}$, Lourdes Conceição Martins $\mathbf{3}$, \\ Marcos Calvo ${ }^{\mathbf{4}}$, Evaldo Stanislau $\mathbf{4}^{4}$ Luiz Amador Pereira ${ }^{\mathbf{3}}$, Marcos Caseiro ${ }^{\mathbf{5}}$
}

DOI: 10.1590/0103-11042020E414

RESUMO A Covid-19 chegou rapidamente à periferia das grandes cidades brasileiras, a qual é socialmente mais vulnerável. A baixa capacidade de testagem resulta na adoção de medidas sem informações consistentes sobre o comportamento da doença e interfere na adoção de ações de controle. Objetivou-se estimar a prevalência de infecção por SARS-CoV-2 na população da Região Metropolitana da Baixada Santista (RMBS) e analisar impactos da vulnerabilidade social e de políticas públicas implementadas em contextos de desigualdades. Estudo de caráter quantitativo, transversal, mediante inquérito sorológico seriado e aplicação de questionário em amostragem populacional estratificada e coleta domiciliar, nos nove municípios da RMBS. Conclui-se que a soroprevalência medida foi de 1,4\% na primeira fase, e de 2,2\% na segunda; permitindo estimar 15 pessoas infectadas para cada caso notificado na primeira fase, $\mathrm{e} 10$ na seguinte. A letalidade foi recalculada para $0,40 \% \mathrm{e}$ 0,48\% em cada fase, aproximando-se da casuística internacional. Pessoas mais vulneráveis são as mais atingidas pela pandemia, devendo ser consideradas: informalidade no trabalho, baixa renda, cor da pele autorreferida como preta ou parda e informações ambivalentes quanto à prevenção. Os resultados reforçam a importância do isolamento social e da adoção de medidas econômicas e sociais protetivas destinadas às populações vulneráveis.

1 Universidade Federal de São Paulo (Unifesp) - São Paulo (SP), Brasil.

arthur.chioro@unifesp.br

2 Faculdade de Ciências Médicas da Santa Casa de São Paulo (FCMSCSP) São Paulo (SP), Brasil.

3 Universidade Católica de Santos (Unisantos) Santos (SP), Brasil

4 Universidade São Judas Tadeu (USJT) - São Paulo (SP), Brasil.

5 Universidade Santa Cecília (Unisanta) - Santos (SP), Brasil.
PALAVRAS-CHAVE Estudos soroepidemiológicos. Infecções por coronavírus. Betacoronavirus. Iniquidade social. Vulnerabilidade social.

ABSTRACT Covid-19 dramatically impacted socially vulnerable regions at the outskirts of large Brazilian cities. Besides, low testing capacity resulted in the lack of proper control measures due to inconsistent information on the disease's behavior. This study aimed to estimate prevalence of SARS-CoV-2 antibodies among the Baixada Santista Metropolitan Region (RMBS) population and the impacts of social vulnerability and public policies implemented within an environment of inequality. A quantitative, cross-sectional study, through a serial serological survey and the application of a questionnaire in stratified population sampling and home drew, in nine municipalities of RMBS. Seroprevalence was $1.4 \%$ in the first and $2.2 \%$ in the second phase, allowing to estimate 15 infected people for each case notified in the first phase, and 10 in the following. Lethality was recalculated to $0.40 \%$ and $0.48 \%$ in each phase, approaching the international rates. Socially vulnerable people were the most affected by the pandemic. Informal work, low income, self-reported skin color as black or brown, and ambivalent information regarding prevention should be considered as risk factors. Our results reinforce the relevance of social isolation and the adoption of protective economic and social measures, especially for socially vulnerable populations.

KEYWORDS Seroepidemiologic studies. Coronavirus infections. Betacoronavirus. Social inequity. Social vulnerability. 


\section{Introdução}

Desde março de 2020, 9 universidades púbicas e privadas da Baixada Santista e de São Paulo, representadas por 24 pesquisadores - em sua maioria docentes do campo da saúde coletiva -, juntamente com o Conselho de Desenvolvimento da Região Metropolitana da Baixada Santista (RMBS) - composto pelos prefeitos dos nove municípios da RMBS e representantes do governo do Estado -, e com o apoio do Parque Tecnológico de Santos, têm-se articulado para investigar a situação da soroprevalência na região, a partir de um inquérito de base populacional, denominado 'Epidemiologia da Covid-19 na Baixada Santista - Epicobs'.

O aparecimento de um novo coronavírus, o SARS-CoV-2, em 2019, deu-se inicialmente na China, seguindo rapidamente para o continente asiático e europeu, até chegar ao Brasil, em 25 de fevereiro de 2020, quando foi notificado o primeiro caso no país. Sua entrada e a disseminação inicial deram-se pelas grandes cidades brasileiras, especialmente as que têm aeroportos internacionais $\mathbf{1}^{\mathbf{1 , 2}}$. A pandemia por Covid-19, como passou a ser denominada a enfermidade que assolou praticamente todos os países, afetou no Brasil - inicialmente as pessoas com mais alta renda, mas experimentou intenso e rápido processo de 'periferização' -, espalhando-se rapidamente para as regiões periféricas das capitais e regiões metropolitanas, marcadas por precárias condições de moradia e alta vulnerabilidade social.

Há uma grande população em situação de vulnerabilidade e excluída de direitos básicos ${ }^{3}$. Para países como o Brasil, superpopuloso e de dimensões continentais, e para os seus entes subnacionais (estados e municípios), que vivem ondas assíncronas epidêmicas, com tempos e distribuição de casos e óbitos de Covid-19 distintas, estudos de base populacional que estimem a soroprevalência nas diversas regiões do País tornam-se imprescindíveis para o enfrentamento da pandemia e podem ser de grande importância para a organização das políticas públicas, em geral, e para o próprio Sistema Único de Saúde (SUS)4.

$\mathrm{Na}$ atual conjuntura social e política vivida no Brasil, essa pandemia tem um grande impacto social, que se reveste de magnitude diferente daquela observada nos países do Hemisfério Norte. Existem fatores que podem estar influenciando a questão, a despeito da existência do SUS, que tem sido fundamental para a proteção da vida da população, entre os quais podem ser destacados: a inexistência de uma política de testagem definida e adequada (testa-se, nacionalmente, apenas pacientes internados, portanto mais graves); a fragilização da rede básica de saúde, resultante da desestruturação do Programa Mais Médicos; os efeitos deletérios do subfinanciamento do SUS, que, a partir de 2016, com a aprovação da Emenda Constitucional 95 (EC-95), passou ao patamar ainda mais grave de desfinanciamento da saúde ${ }^{5}$; a incapacidade de garantir equipamentos de proteção individual e outros insumos fundamentais para que os trabalhadores do SUS pudessem efetuar com segurança seu papel no enfrentamento da pandemia.

Os fatores que mais incidem sobre a resposta brasileira à pandemia, todavia, originam-se pela conjugação de dois outros fatores. Em primeiro lugar, a profunda desigualdade social existente no Brasil, que se expressa na existência de uma grande população vulnerável, excluída de direitos básicos essenciais. Em segundo, a postura negacionista do presidente da república, minimizando a gravidade da pandemia de Covid-19 e se colocando como o maior obstáculo à adoção de medidas de controle, em especial, as de caráter não medicamentoso, como o isolamento social.

Mesmo tendo aplicado políticas de isolamento na região, por iniciativa dos prefeitos e do governador do estado, a curva de incidência da Covid-19 na RMBS tem sido ascendente. Ao serem questionadas pelo governo federal, tais medidas perdem força e credibilidade por parte da população ${ }^{2}$, desorientando-a quanto à adesão às medidas indicadas pela Organização Mundial da Saúde (OMS). Além disso, áreas 
com extrema desorganização urbana e precárias condições habitacionais, como favelas e cortiços, sem alguns serviços básicos, como coleta de água e esgoto, são duramente impactadas, uma vez que possuem um número maior de pessoas vivendo no mesmo domicílio, o que torna mais difícil o isolamento social.

A RMBS, criada por lei em 1996, com população de 1.865.397, é uma região litorânea próxima à cidade de São Paulo, composta por 9 municípios - Bertioga, Cubatão, Guarujá, Itanhaém, Mongaguá, Peruíbe, Praia Grande, Santos e São Vicente ${ }^{6}$.

As principais atividades econômicas estão relacionadas com o polo industrial e petroquímico de Cubatão, com o Porto de Santos e com o turismo balneário, favorecidas pela localização muito próxima da Grande São Paulo e por sistema de rodovias que facilita o permanente trânsito de pessoas e cargas.

o Índice de Desenvolvimento Humano Municipal (IDHM) da região se situa na faixa de Alto Desenvolvimento Humano (0,777 em 2010). Dos três componentes que constituem o índice longevidade, educação e renda -, o mais elevado é longevidade, que atingiu 0,842 , em virtude da esperança de vida ao nascer, que, em 2010, era de 75,5 anos, refletindo o perfil de envelhecimento da população da região, que apresenta $15 \%$ de sua população acima de 60 anos.

Apesar do alto IDHM, a desigualdade regional se destaca ao serem analisadas as Unidades de Desenvolvimento Humano (UDH), já que $45 \%$ destas se encontram na faixa de Muito Alto Desenvolvimento Humano, enquanto $30 \%$ ainda se situam na faixa de médio grau de desenvolvimento. Mesmo em Santos, município sede da região, que se encontra na $6^{a}$ posição entre os 5.570 municípios brasileiros e possui bairros com IDHM de 0,906, persistem regiões com IDH de até 0,699 . Em relação a indicadores de vulnerabilidade social, a região ainda possui $18,2 \%$ da população considerada vulnerável à pobreza e $3,25 \%$ de crianças como extremamente pobres ${ }^{8}$.

Trata-se, portanto, de uma região rica e desenvolvida, mas com grande desigualdade social e econômica. Dessa forma, o aumento exponencial dos casos de Covid-19 e a migração de sua ocorrência para áreas periféricas e mais vulneráveis têm seguido o padrão nacional.

A baixa testagem adotada no País, restrita aos casos de maior gravidade, impede que medidas sanitárias para prevenção, controle e organização do sistema de saúde sejam adotadas tendo como base informações epidemiológicas consistentes e seguras. Estimativas disponíveis em estudos internacionais não conseguem captar as diferenças significativas impostas pela realidade brasileira 9 .

O objetivo inicial do estudo, de base populacional, foi estimar a prevalência de infecção por SARS-CoV-2 na população da RMBS, por meio de inquérito sorológico seriado em amostragem populacional estratificada por sorteio aleatório e coleta domiciliar. No presente artigo, além de apresentar os dados da soroprevalência referentes às duas primeiras fases da pesquisa, pretende-se analisar, em especial, impactos da vulnerabilidade social e de políticas públicas implementadas para enfrentamento da pandemia de Covid-19 em contextos de desigualdades.

$\mathrm{O}$ artigo procura, assim, enfatizar a desigualdade social em meio à pandemia, ao considerar o peso da política nacional de enfrentamento que se dá sem condução comum, com ambivalência das informações e a falta de uma política de apoio econômico emergencial efetivo para as populações mais vulneráveis.

\section{Material e métodos}

O estudo, de caráter quantitativo, apresenta os resultados de duas etapas de um estudo planejado para ser realizado em quatro fases, com intervalo de 15 dias. Em cada fase, foi realizado um estudo transversal em todos os municípios que constituem a RMBS.

A determinação do tamanho amostral foi realizada, inicialmente, utilizando-se o pacote estatístico EPIINFO - versão 7.2, software livre do CDC-Atlanta (EUA). A amostra 
populacional randomizada foi construída de forma estratificada por idade, sexo e modo de vida, a partir da população estimada no Censo Demográfico de 2010 para cada um dos 9 municípios da Baixada Santista, da ordem de 1.831.884 habitantes.

Utilizou-se uma estimativa de frequência de $7 \%$, e um erro marginal aceitável de $2 \%$, admitindo-se uma amostragem randomizada estratificada por conglomerados, o efeito do desenho e o efeito do conglomerado igual a 1 (conforme sugestão do pacote estatístico). Chegou-se, assim, à amostragem inicial, para a fase 1 , de 2.432 e, na fase 2 , de 2.500 pessoas como população amostral.

Para detecção de anticorpos, foi utilizado o teste de Fluxo Lateral (WondfoR), escolhido entre aqueles aprovados em Resolução $n^{\circ}$ 777/2020 da Agência Nacional de Vigilância Sanitária (Anvisa) ${ }^{\mathbf{1 0}}$ e selecionado como adequado por sua disponibilidade após validação local em pacientes com RT-PCR positivo para SARS-CoV-2 e com mais de 14 dias de sintomas.

A coleta de sangue total por punção digital foi realizada observando-se as orientações do fabricante. Os resultados foram lidos visualmente até 15 minutos, e não mais que 20 minutos após a coleta de material, e toda a equipe de campo recebeu treinamento para o uso e leitura dos testes, cuja aplicação ocorreu no mesmo intervalo de tempo em todos os municípios da região, nas duas fases realizadas e que se constituem objeto da presenta análise.

Entre o momento da coleta e a análise do resultado, foi aplicado um questionário semiestruturado. Foram levantadas condições sociais, econômicas e demográficas, como renda, vinculação ao trabalho, perda de emprego e renda, condições de moradia, expressa pelo número de cômodos e de pessoas convivendo na mesma residência, acesso às informações de prevenção e cuidado da Covid-19 e a forma de uso de serviços de saúde (públicos e privados). Sintomas de gripe, adesão ao isolamento social e uso de máscaras também foram pesquisados. O questionário foi testado previamente, e os aplicadores foram submetidos a treinamento antes do início da pesquisa.

As variáveis foram descritas por meio de frequências absolutas, relativas e respectivos Intervalos de Confiança (IC95\%). As variáveis numéricas foram apresentas por médias e desvio padrão.

O estudo obteve financiamento do Parque Tecnológico de Santos, entidade pública, sem fins lucrativos, que fez a aquisição direta e disponibilização dos testes aos pesquisadores. Contou, ainda, com o apoio da Diretoria Regional de Saúde da Secretaria de Estado da Saúde de São Paulo e das secretarias municipais de saúde, em especial, para realização do trabalho de campo, realizado por equipes das áreas de vigilância em saúde e atenção básica, treinados e supervisionados pelos pesquisadores.

A pesquisa foi aprovada pelo Comitê de Ética em Pesquisa da Universidade Lusíada, Santos, SP, sob o n ${ }^{\circ}$ 3.992.985. Todos os participantes assinaram Termo de Consentimento Livre e Esclarecido.

\section{Resultados}

Na primeira fase do estudo, realizada entre 29 de abril e $1^{\circ}$ de maio de 2020; e, simultaneamente, nos 9 municípios da Baixada Santista, foram entrevistados e coletados testes rápidos em amostra composta por 2.341 pessoas, com idade média de $37,78( \pm 19,98)$ anos, variando de 0 a 93 anos. A maior parte dos respondentes era mulher (53,5\%) e tinha idade entre 25 e 60 anos $(55,3 \%)$. A maioria não tinha vínculo formal de trabalho (71,1\%), morava em residência com 4 ou mais cômodos $(84,2 \%)$ e possuía renda familiar de até 3 salários mínimos (71,9\%). Desde o início da pandemia de Covid-19, 19,8\% dos entrevistados relataram que algum membro da família perdeu o emprego e que $8,1 \%$ tiveram parte da renda comprometida (tabela 1).

$\mathrm{Na}$ segunda fase, realizada entre 13 e 15 de maio, a amostra para realização de testes e entrevistas foi composta de 2.415 
pessoas, com idade média de 37,55 , com uma distribuição equitativa do sexo. Em relação à caracterização sociodemográfica, a maioria relatou residir em local com 4 ou mais cômodos (88,9\%); 71,1\% tinham renda familiar de até 3 salários mínimos e
$77,7 \%$ não tinham trabalho formal. Nessa segunda fase, o percentual de entrevistados que perdeu o emprego ou teve alguém que ficou desempregado na família elevou-se para $21,8 \%$, e $7,6 \%$ relataram perda de parte da renda familiar (tabela 1).

Tabela 1. Análise descritiva dos fatores sociodemográficos em relação às variáveis isolamento, quantidade de cômodos, renda familiar, trabalho e perda de renda na pandemia de Covid-19 na RMBS. Epicobs, 2020

\begin{tabular}{|c|c|c|c|}
\hline Variáveis & Fase 1 - № (\%) & Fase 2 - № (\%) & Total - № (\%) \\
\hline \multicolumn{4}{|l|}{ Isolamento } \\
\hline Não Informado & $115(4,9)$ & $1(0,0)$ & $116(2,4)$ \\
\hline Não & $859(36,7)$ & $285(11,8)$ & $1144(24,0)$ \\
\hline Sim & $1368(58,4)$ & $2129(88,2)$ & $3497(73,5)$ \\
\hline \multicolumn{4}{|l|}{ Quantidade de cômodos } \\
\hline 1 & $22(0,9)$ & $22(0,9)$ & $44(0,9)$ \\
\hline 2 & $92(3,9)$ & $117(4,8)$ & $209(4,4)$ \\
\hline 3 & $255(10,9)$ & $258(10,7)$ & $513(10,8)$ \\
\hline 4 ou mais & $1973(84,2)$ & $2017(83,5)$ & $3990(83,9)$ \\
\hline \multicolumn{4}{|l|}{ Renda familiar } \\
\hline de até 1 salário mínimo & $674(28,8)$ & $712(29,5)$ & $1386(29,1)$ \\
\hline entre 2 e 3 salários mínimos & $1009(43,1)$ & $1004(41,6)$ & $2013(42,3)$ \\
\hline de 3 ou mais salários mínimos & $595(25,4)$ & $653(27,0)$ & $1.248(26,3)$ \\
\hline de 10 ou mais salários mínimos & $64(2,7)$ & $45(1,9)$ & $109(2,3)$ \\
\hline \multicolumn{4}{|l|}{ Trabalho formal } \\
\hline Não & $1665(71,1)$ & $1863(77,1)$ & $3528(74,2)$ \\
\hline Sim & $677(28,9)$ & $551(22,8)$ & $1228(25,8)$ \\
\hline \multicolumn{4}{|l|}{ Perdeu parte da renda } \\
\hline Não & $1675(71,5)$ & $1704(70,6)$ & $3379(71,0)$ \\
\hline Perdeu parte da renda & $203(8,7)$ & $184(7,6)$ & $387(8,1)$ \\
\hline Sim & $464(19,8)$ & $526(21,8)$ & $990(20,8)$ \\
\hline
\end{tabular}

Fonte: Elaboração própria.

Em relação às medidas de isolamento, na primeira fase, $58,4 \%$ dos entrevistados relataram que não saíram de casa ou saíram apenas para comprar comida e remédios, e 94,1\% fizeram uso de máscara, a maioria de origem caseira, atendendo às recomendações das autoridades sanitárias locais e estadual. Já na segunda fase, o isolamento social foi cumprido por $88,2 \%$ dos entrevistados, e $98,1 \%$ relataram o uso de máscaras (tabela 1)

Nas duas fases, a maioria dos sujeitos entrevistados não tinha comorbidade preexistente ( $70,8 \%$ e $73,6 \%)$, e o percentual dos que conheciam alguém com Covid-19 foi de 29,8\% e $34,9 \%$ respectivamente.

Conforme pode ser observado na tabela 2 , na primeira fase do estudo Epicobs, 33 pessoas apresentaram testes positivos/reagentes para 
Covid-19, indicando soroprevalência de 1,4\%, com IC95\% $(0,93-1,93)$. Na segunda fase do estudo, a soroprevalência foi de $2,2 \%$, com IC95\% (0,93-1,93).

Tabela 2. Número e percentual de casos positivos, números estimados de infectados, de infectados por habitante e relação entre casos estimados/notificados, segundo a fase do estudo. RMBS, 2020

\begin{tabular}{lrr}
\hline Epicobs & Fase 1 (29 - 30/4) & Fase 2 (13 - 15/05) \\
\hline Testes positivos & 33 & 54 \\
Percentual com anticorpos & 1,4 & 2,2 \\
Número com anticorpos & 25.823 & 40.608 \\
Um infectado para cada ( ) hab. & 69 & 45 \\
Relação estimados/notificados & 15 & 10 \\
\hline
\end{tabular}

Fonte: Elaboração própria.

Entre os 33 entrevistados com resultados reagentes na primeira fase, $54,5 \%$ eram do sexo masculino, $84,8 \%$ residiam em residências com 4 ou mais cômodos, $75,8 \%$ recebiam até 3 salários mínimos, $54,5 \%$ não tinham trabalho formal, $65,6 \%$ relataram que estavam respeitando o isolamento social e $69,7 \%$ responderam depender do SUS exclusivamente para o cuidado com sua saúde.

Os resultados observados na segunda fase do estudo indicam que, entre os 54 entrevistados com resultados reagentes, $57,4 \%$ eram do sexo feminino, invertendo a maior prevalência entre homens observada na fase anterior; $88,9 \%$ residiam em residência com 4 ou mais cômodos, $75,8 \%$ recebiam até 3 salários mínimos, $77,8 \%$ não tinham trabalho formal, $68,6 \%$ relataram respeitar o isolamento social e $68,5 \%$ informaram que dependiam do SUS para o cuidado com sua saúde, seguidos de $24,1 \%$ que tinham seguro privado de saúde.

Entre os entrevistados com testes positivo para Covid-19, 68,5\% alegaram ter apresentado sintomas gripais nos últimos 30 dias.

$\mathrm{Na}$ fase 1 do estudo, 63,6\% dos sujeitos com resultados positivos realizaram isolamento, sendo que apenas $9,1 \%$ não saíram de casa; $84,8 \%$ residiam em casas com 4 ou mais cômodos e $64,7 \%$ residiam com 4 a 5 pessoas,
$36,4 \%$ recebiam até 1 salário mínimo, quase $70 \%$ dependiam apenas do SUS, 66,7\% tiveram sintomas de gripe nos últimos 30 dias e $54,5 \%$ das pessoas com testagem positiva não procuraram serviço de saúde.

$\mathrm{Na}$ fase 2, entre os que tiveram resultado positivo, $94,4 \%$ realizaram isolamento, sendo que apenas $9,3 \%$ não saíram de casa; $88,9 \%$ residiam em casas com 4 ou mais cômodos e $50 \%$ residiam com 4 a 5 pessoas, $29,6 \%$ recebiam até 1 salário mínimo e $37 \%$ recebiam de 2 a 3 salários mínimos, quase $68,5 \%$ dependiam apenas do SUS, $68,5 \%$ tiveram sintomas de gripe nos últimos 30 dias e $63 \%$ das pessoas positivas não procuraram serviço de saúde.

A maior parte dos testes positivos se deu entre os que se definiram como pretos e pardos $(61,2 \%)$, ainda que a amostra indicasse distribuição equitativa entre estes e os que se definiram como brancos, sendo que, destes, apenas $37 \%$ tiveram resultados reagentes.

\section{Discussão}

As medidas desenvolvidas pelos gestores municipais e estaduais do SUS para o enfrentamento da pandemia de Covid-19 no Brasil têm sido implementadas praticamente às cegas, sem 
informações seguras e consistentes, em virtude da baixa capacidade de testagem sorológica, tanto para a realização de diagnóstico em casos leves e moderados como para análise da dimensão da população já infectada e ainda suscetível.

Tal afirmativa pode ser corroborada pela quantidade de testes realizados no País, que, durante praticamente todo o período da pesquisa, manteve-se em apenas 1.597 testes por 1 milhão de habitantes ${ }^{11}$. Decorridos vários meses do início da pandemia, o Brasil ainda não conta com uma efetiva política nacional de testagem em massa, que tem sido feita errática e pontualmente por alguns municípios e estados; e, na maioria do País, de forma restrita aos casos graves/internados. Essa situação foi determinada pela falta de investimentos do Ministério da Saúde na rede nacional de laboratórios públicos, ainda semiautomatizada e com baixa capacidade de processamento de exames (6.700 exames/dia, quando a necessidade estimada pelo próprio Ministério da Saúde é de 50 mil exames/dia) ${ }^{\mathbf{1 2}}$, para os exames de biologia molecular (RT-PCR), e a incapacidade de adquirir testes rápidos e apoiar estados e municípios na realização de inquéritos sorológicos. É fruto, para além da incapacidade e descompromisso dos gestores do SUS em âmbito nacional, dos efeitos deletérios da política de austeridade fiscal, sustentada pelo desfinanciamento da saúde observado desde a aprovação da EC-95, que congelou os gastos com políticas públicas por 20 anos $^{13}$.

O crescimento da taxa de soroprevalência observado entre a primeira e a segunda fase do estudo Epicobs (de 1,4\% para 2,2\%) expressa um crescimento da ordem de $63 \%$, em apenas 15 dias, indicando a força de transmissão da Covid-19 e que há um número significativamente superior de pessoas infectadas na região em relação aos casos até então notificados. A soroprevalência, com base em anticorpos, demonstra que há mais pessoas infectadas em comparação às notificações oficiais ${ }^{3}$. Alerta, outrossim, para o percentual da população potencialmente vulnerável à enfermidade ainda elevado, mesmo que o número de casos graves e que exigem cuidados críticos já impacte consideravelmente a rede de serviços de saúde públicos e privados da RMBS, advertindo também que a pandemia ainda deverá tardar a atingir seu pico máximo e iniciar a fase de regressão.

O estudo possibilitou estimar, na primeira fase, a existência de 25.823 infectados na RMBS, o que corresponde a 1 pessoa infectada por SARS-CoV-2 para 69 habitantes, e uma relação estimada de 15 casos para 1 notificado. Na fase seguinte, foi possível estimar que o número de infectados subiu para 40.608 , correspondendo a 1 pessoa infectada para 45 habitantes, e uma relação estimada de 10 casos para 1 notificado, caracterizando a enorme subnotificação da pandemia de Covid-19.

A partir dos dados empíricos obtidos, a letalidade foi recalculada e estimada na ordem de $0,40 \%$ na primeira fase, e de $0,48 \%$ na segunda fase, indicando que a relação de óbitos a partir do total de casos oficialmente notificados no período em que foi realizada essa etapa do estudo, da ordem de $7,2 \%$ e $6,3 \%$, respectivamente, estava superestimada; e que o Epicobs permitiu realinhar os dados de letalidade encontrados em outros países"1.

A confirmação diagnóstica, restrita aos casos moderados e graves, impede o reconhecimento da real situação epidemiológica e falseia substantivamente a letalidade da enfermidade.

Pela proximidade e características populacionais, pode-se inferir que os achados do estudo para a RMBS podem expressar o que está acontecendo em toda a Região Metropolitana de São Paulo e mesmo em outras regiões do País. Trata-se, pois, de estudo inédito no Hemisfério Sul, ainda mais se considerarmos o valor total de entrevistados, totalizando 4.757 pessoas testadas nas duas fases.

A despeito da maior adesão ao uso de máscara $(98,1 \%)$ na segunda fase, deve-se ressaltar que houve redução dos entrevistados que indicaram adesão ao isolamento (68,6\%), e um aumento de $8,8 \%$ dos que saíram para compras que não fossem relacionadas com a alimentação ou com medicamentos. Nem o aumento de $42 \%$ dos entrevistados 
que alegaram conhecer alguém com Covid-19, observado entre a primeira e a segunda fase, parece ter impactado decisivamente para o cumprimento do isolamento social.

Os dados revelados pela pesquisa permitiram aos gestores do SUS e prefeitos dos municípios da RMBS tomarem decisões sobre as políticas públicas, como, por exemplo, orientar a sustentação do isolamento social e o uso de máscaras pela população, medidas fortemente recomendadas pelos pesquisadores ao tornarem públicos os resultados de cada fase, por meio das mídias sociais, ainda que tenham frustrado expectativas de determinadas autoridades municipais e do setor empresarial da RMBS que esperavam que os resultados dessem sustentação científica à flexibilização do isolamento e ao retorno das atividades econômicas.

A pesquisa permitiu, ainda, orientar medidas visando à organização dos serviços de saúde, dos espaços mais adequados para a divulgação das orientações de cuidados e prevenção do contágio pelo SARS-Cov-2 e até para a distribuição ordenada de insumos que pudessem ajudar a conter a velocidade de expansão da pandemia.

É imprescindível discutir que a adoção dessas medidas se deu em meio ao tensionamento político provocado pelo presidente da república, que passou a hostilizar autoridades estaduais e municipais que adotaram medidas baseadas nas orientações da OMS, o que culminou com a necessidade de intervenção do Supremo Tribunal Federal. O posicionamento de Jair Bolsonaro, fundamentado em uma postura negacionista, resultou em incitamento ao não cumprimento do isolamento social e do uso de máscaras, chegando ao cúmulo de impor protocolo para uso de medicamentos sem eficácia e segurança comprovadas, recomendar abertura de caixões e a invasão de hospitais para que fossem denunciadas a 'fabricação' de vítimas e óbitos pelos governadores e prefeitos. Embora difícil de ser mensurada, tal postura, associada à fragilidade de respostas e à insuficiência de auxílios emergenciais para proporcionar às populações mais vulneráveis condições adequadas para o cumprimento do isolamento social recomendado, impactaram decisivamente no enfrentamento da pandemia. O chefe do Executivo se tornou, indubitavelmente, em um inimigo mais perigoso e difícil de ser combatido do que o SARS-CoV-2.

As constantes trocas de ministros da saúde em plena vigência da pandemia e a recente militarização do Ministério da Saúde, ocupado agora por profissionais sem qualificação e experiência técnica na área da saúde pública, e sem a necessária vivência na gestão SUS, fragilizam profundamente a capacidade do Ministério da Saúde em coordenar o sistema nacional de saúde e a resposta brasileira ao enfretamento da pandemia, que exige a articulação e pactuação interfederativa, envolvendo e comprometendo as secretarias estaduais e municipais de saúde, outros órgãos públicos e a própria sociedade. Essas são questões de extrema importância para a gestão e impactam diretamente na organização das políticas públicas de saúde, tais como a distribuição e o acesso de leitos de Unidade de Terapia Intensiva (UTI), hospitais de campanha, compra de insumos, medicamentos, entre outros.

É relevante destacar que, até o momento, poucos estudos foram realizados em países do Hemisfério Sul para estimar a prevalência de infecção por SARS-CoV-2. Mais raros ainda são os conduzidos em países de baixa e média rendas, e que tentam fazer a relação da pandemia com a condução das políticas públicas e as populações mais vulneráveis. $\mathrm{Na}$ atual conjuntura vivida no Brasil, a pandemia tomou um vulto singular em relação à maioria dos países, especialmente os localizados no Hemisfério Norte, pois além da falta de uma política de testagem adequada, de respostas governamentais fragilizadas e, por vezes, caótica, trata-se de um país continental, marcado por profunda heterogeneidade regional e por desigualdades econômicas e sociais acentuadas.

Ao comparar as características sociodemográficas nas duas fases do estudo, observou-se o impacto imediato da pandemia nas condições econômicas, expressas pela diminuição das pessoas com vínculo formal de trabalho, de 
$19,0 \%$ e $21,8 \%$ respectivamente. Afinal, uma em cada cinco pessoas perdeu o emprego a partir da pandemia de Covid-19, e o impacto na diminuição de renda familiar também se fez sentir para os entrevistados (8,1\% e 7,6\% respectivamente), o que se revela ainda mais significativo quando se considera que o país já vinha mergulhado em grave crise financeira e em altos níveis de desemprego.

Essa análise nos remete necessariamente para os efeitos da pandemia de Covid-19 em um país marcado por enormes desigualdades sociais, que se expressam substantivamente nas pessoas que vivem em situação de maior vulnerabilidade social, como moradias extremamente precárias, falta de saneamento básico, insegurança alimentar, entre outras. A grande diferença entre testes reagentes entre pretos e pardos $(61,0 \%)$ e brancos $(37,7 \%)$, identificada pelo Epicobs, é marcadora da desigualdade racial, que também se expressa como iniquidade social.

Dos casos reagentes, $62,8 \%$ moravam em casa de até 4 cômodos, sendo que, em $55,7 \%$, viviam de 3 a 4 pessoas; $77,7 \%$ dos positivos ganham até 3 salários mínimos; 69,8\% utilizam exclusivamente o SUS; e $23,3 \%$ têm plano de saúde, mas também utilizam o SUS, caracterizando inequivocamente o maior acometimento em população com maior vulnerabilidade social. Soma-se a esse quadro o fato de $69,8 \%$ dos indivíduos com sorologia positiva trabalharem na informalidade, sem qualquer vínculo empregatício.

Considerando-se o impacto econômico da pandemia que os dados empíricos apresentam, torna-se indispensável - para além das medidas sanitárias, medicamentosas ou não - a adoção de políticas de bem-estar social que apoiem a sobrevivência das pessoas e ampliem a capacidade de se manterem em isolamento, em particular diante da alta prevalência da população que não possui anticorpos positivos para o SARS-Cov-2 e que, portanto, ainda é suscetível à enfermidade.

Esse importante impacto econômico da pandemia na vida das pessoas aponta para a necessidade de ações de políticas públicas inclusivas e adequadas para as populações mais vulneráveis, como as que foram implantadas, por exemplo, em Portugal, na Argentina e em diversos outros países. Essas políticas devem incluir benefícios emergenciais específicos, para além dos $\mathrm{R} \$ 600,00$ por três meses, disponibilizados pelo governo federal após intensa pressão do Congresso Nacional, aos que tiveram maiores perdas de renda e/ou que já se encontravam em situação de exclusão social, desempregados, subempregados ou em trabalho informal, e que foram dura e desigualmente afetados pela pandemia e pela inércia governamental em produzir políticas substantivas para mitigação dos deletérios efeitos econômicos e sociais da Covid-19 sobre as populações vulneráveis.

Mesmo com as adversidades apontadas, 0 isolamento social se manteve no período da pesquisa e foi cumprido pela população em mais de $60 \%$, que, de alguma forma, procura seguir as orientações das autoridades públicas e de saúde. Também chama a atenção que as pessoas, mesmo com as dificuldades econômicas vivenciadas, mantêm-se acreditando especialmente nos dados disponíveis, nos profissionais de saúde e na ciência ${ }^{2}$. Um exemplo disso é o uso de máscaras, que vem sendo utilizado sempre ao sair de casa pela maioria da população.

A despeito de não ter sido desenvolvida nenhuma campanha de comunicação social pelo governo federal ou pelo Ministério da Saúde, que possui dotação orçamentária específica e tem a responsabilidade de manter a população devidamente informada, foi relatada pelos entrevistados uma percepção de conhecimento e informação acerca da pandemia. O meio pelo qual mais buscaram adquirir essas informações foi a televisão, seguida da orientação por profissionais de saúde e do uso das redes sociais.

Esses resultados nos direcionam ao questionamento sobre a importância da correta comunicação pelos meios de comunicação, em geral, e ao mesmo tempo dos prejuízos 
causados pelas fake news, que podem induzir práticas inadequadas para o enfrentamento da pandemia. Revelam, ainda, o importante papel que poderia ser representado pela atenção básica, em especial pelas Equipes de Saúde da Família e pelos os Agentes Comunitários de Saúde, pela potencial capacidade de acolher, informar e orientar adequadamente a população mais vulnerável.

Considerando-se que a maioria dos indivíduos soroprevalentes relatou sintomas Influenza-Like nos últimos 30 dias e que não procuraram serviços de saúde ou não receberam a visita de profissionais da atenção básica em seu domicílio, constata-se que o SUS acaba perdendo a possibilidade de identificar novos casos, testá-los e isolá-los, procurando assim interromper a cadeia de transmissão da Covid-19, papel fundamental que deveria estar sendo desempenhado pelas equipes de saúde da família.

É importante destacar que, quando os entrevistados pelo Epicobs precisaram usar o serviço de saúde, o fizeram pela atenção primária, por intermédio das Unidades Básicas de Saúde. Entretanto, mais de 80\% dos entrevistados não procuraram nenhum serviço de saúde, o que nos faz pensar que a população está protegendo os serviços hospitalares, provavelmente por considerarem e reconhecerem a importância de manter os profissionais focados no enfrentamento da pandemia. Por meio da utilização de protocolos de atendimento, manejo e acompanhamento dos casos da Covid-19, incluindo os que estiverem em isolamento domiciliar, com evolução benigna do quadro clínico, poder-se-ia evitar a superlotação dos serviços hospitalares e a busca desnecessária por serviços de urgências por usuários de baixo risco clínico.

Municípios que não retraíram a oferta de serviços básicos e mantiveram estratégias efetivas de cuidados básicos, inclusive em âmbito domiciliar, puderam fazer significativa diferença no enfrentamento da pandemia de Covid-19 e no cuidado e controle de outros problemas de saúde que continuaram a ser observados, em particular em relação às condições crônicas.

Ainda que não tenha sido objetivo específico do estudo, pode-se observar que a atuação da atenção básica nos municípios da RMBS tem sido heterogênea, mas parece interferir decisivamente na capacidade de resposta e nos resultados. Lamentavelmente, não há coordenação nacional por parte do Ministério da Saúde; e, mantendo a postura observada nas duas últimas décadas no estado de São Paulo, a Secretaria de Estado da Saúde não reconhece a atenção primária à saúde como sua responsabilidade e despreza a participação da rede básica na resposta à pandemia. É como se a atenção básica fosse um 'sujeito ausente' nesse processo.

Outro dado fundamental é a quantidade expressiva de pessoas entrevistadas que usam o sistema público para cuidar da saúde, já que mais de $60 \%$ dependem do SUS exclusivamente para ter acesso aos serviços de saúde; e há ainda aqueles que possuem saúde suplementar e usam o SUS e o seguro privado de saúde conjuntamente ${ }^{\mathbf{1 4}}$. Pode-se, assim, perceber a importância de valorizar o SUS, preservar os serviços, e a necessidade de investimentos, treinamentos e garantia da oferta de Equipamentos de Proteção Individual (EPI), cuidando efetivamente dos profissionais de saúde envolvidos no enfrentamento da pandemia. Esses achados se adequam ao perfil da população brasileira, da ordem de aproximadamente $70 \%$, que depende do SUS para seus cuidados de saúde ${ }^{15-17}$.

Cabe, por fim, destacar que, a despeito do discurso adotado por muitos gestores municipais e estaduais - inclusive da RMBS - de que seguiriam as recomendações científicas e por meio delas orientariam as decisões a serem tomadas no enfrentamento da pandemia de Covid-19, os resultados apresentados na primeira fase e, principalmente, aqueles que expressaram o agravamento da situação sanitária na segunda parecem ter frustrado expectativas de que o resultado da pesquisa Epicobs daria sustentação para a flexibilização 
do isolamento social e retomada das atividades econômicas. Prefeitos de três municípios da região, contra as orientações indicadas pelos pesquisadores e que foram tornadas públicas por meio dos meios de comunicação social regional e nacional, ainda assim tomaram a decisão de flexibilizar o isolamento, cujos impactos exigirão atenta análise nas próximas fases programadas da pesquisa.

\section{Considerações finais}

O presente estudo permitiu considerar, nessa primeira etapa do Epicobs em que duas fases foram realizadas, que, embora a prevalência de pessoas infectadas pela Covid-19 possa ser considerada relativamente alta em relação a estudos populacionais realizados em outros países $^{\mathbf{1 7}}$ e, no caso do Brasil, no estado do Rio Grande do Sul18, o percentual da população potencialmente vulnerável à enfermidade ainda é consideravelmente elevado e que a pandemia ainda deverá tardar a atingir seu pico máximo e iniciar a fase de regressão.

$\mathrm{O}$ inquérito populacional permitiu reconhecer a prevalência de infecção da doença na RMBS e estimar que o número de infectados era, ao final da segunda fase do estudo, dez vezes maior do que o de casos notificados oficialmente. Possibilitou, ainda, estimar a existência de uma pessoa infectada por Covid19 para cada 45 habitantes, e apresentar uma letalidade da doença bem menor ante a calculada a partir das notificações, em que há predomínio de casos moderados e graves notificados, aproximando-a da casuística internacional.

Espera-se que a realização seriada de mais duas etapas de investigação, previstas na continuidade do estudo, possa suprir possíveis problemas e limites metodológicos encontrados na produção e análise do material empírico, como produzir respostas a respeito do comportamento epidêmico e do alcance das medidas sanitárias adotadas no enfretamento da Covid-19.

Os resultados aqui apresentados reforçam a importância da adoção e manutenção de medidas não medicamentosas, tais como o isolamento social, imposto pelos governos regionais e locais, e o uso de máscaras faciais de forma universal pela população.

Para países de baixa e média rendas do Hemisfério Sul, tais recomendações revestem-se de importância. No caso brasileiro mais ainda, dada a postura adotada pelo governo federal, em particular, pelo presidente brasileiro Jair Bolsonaro, que não recomenda a adoção de isolamento social e de interrupção das atividades econômicas não essenciais, medidas praticadas exitosamente até aqui pelos países no enfrentamento da pandemia de Covid-19, sob orientação da OMS. Reforçam, ainda, a necessidade de enfrentar a desigualdade social e garantir medidas econômicas e sociais que permitam as condições necessárias para proteger a saúde e a vida das populações em situação de vulnerabilidade.

Nesse contexto, resta saber o quanto as autoridades vinculadas aos governos subnacionais conseguirão resistir às pressões econômicas e interesses eleitorais, turbinados pelo orbe de seguidores negacionistas do presidente da república, e conseguirão fazer valer o interesse público, preservando e defendendo a vida, em particular, das populações em situação de maior vulnerabilidade.

\section{Colaboradores}

Chioro A (0000-0001-7184-2342)*, Calife K (0000-0002-7038-8069)*, Barros CRS (0000-0002-1582-2010)*, Martins LC (00000001-9996-2725), * Calvo M, (0000-0001-62255410)*, Stanislau E (0000-0003-3642-5476)*, Pereira LA (0000-0002-8172-5841)*, Caseiro M (0000-0003-2950-4299)*, contribuíram igualmente para a elaboração do manuscrito. 


\section{Referências}

1. Burki T. COVID-19 in Latin America. Lancet Infect Dis [internet]. 2020 [acesso em 2020 jun 18]; 20(5):547-548. Disponível em: https://www.thelancet.com/journals/laninf/article/PIIS14733099(20)30303-0/fulltext.

2. The Lancet. COVID-19 in Brazil: "So what? The Lancet [internet]. 2020 [acesso 2020 jun 12]; 395:1461. Disponível em: https://www.thelancet.com/pdfs/ journals/lancet/PIIS0140-6736(20)31095-3.pdf.

3. Mellan T, Hoeltgebaum H, Mishra S, et al. Report 21: Estimating COVID-19 cases and reproduction number in Brazil. [internet]. 2020. [acesso 2020 jun 21]. Disponível em: http://hdl.handle. net/10044/1/78872.

4. Costa AM, Rizzotto MLF, Lobato L. Na pandemia da Covid-19, o Brasil enxerga o SUS. Saúde debate [internet]. 2020 [acesso 2020 jun 30]; 44(125): 289-296.

5. Menezes APR, Moretti B, Reis AAC. O futuro do SUS: impactos das reformas neoliberais na saúde pública - austeridade versus universalidade. Saúde debate [internet]. 2019 [acesso 2020 jun 21]; 43(esp5):5870. Disponível em: https://scielosp.org/article/ sdeb/2019.v43nspe5/58-70/.

6. Brasil. Ministério da Saúde. Informações de Saúde: Estimativas de população [internet]. [data desconhecida]. [acesso em 2020 jun 17]. Disponível em: http://tabnet.datasus.gov.br/cgi/tabcgi.exe?ibge/ cnv/poptsp.def.

7. Brasil. Ministério da Saúde, Secretaria de Vigilância em Saúde. CGIAE. Estimativas preliminares [internet]. [data desconhecida]. [acesso em 2020 jun 17]. Disponível em: http://tabnet.datasus.gov.br/cgi/tabcgi.exe?novapop/cnv/popbr.def.

8. Atlas do Desenvolvimento Humano do Brasil. Região Metropolitana da Baixada Santista [internet]. [data desconhecida]. [acesso em 2020 jun 18]. Disponível em: http://www.atlasbrasil.org.br/2013/pt/ perfil_rm/87\#vulnerabilidade.
9. Ogris G. Spread of SARS-CoV-2 in Austria. PCR tests in a representative sample Study report. Vienna: SORA Institute for Social Research and Consulting. [internet]. 2020 [acesso em 2020 jun 24]. Disponível em: https://www.sora.at/fileadmin/downloads/ projekte/Austria_Spread_of_SARS-CoV-2_Study_ Report.pdf.

10. Brasil. Ministério da Saúde, Agência Nacional de Vigilância Sanitária, Gerência-Geral de Tecnologia de Produtos para Saúde. Resolução no. 777, de 18 de março de 2020. Deferir as petições relacionadas à Gerência-Geral de Tecnologia de Produtos para a Saúde [internet]. [acesso em 2020 abr 12]. Disponível em: http://www.planalto.gov.br/CCIVIL_03/Portaria/Resolucao\%20n\%C2\%BA\%20 777-ANVISA.htm.

11. Wordometer. COVID-19 Coronavirus Pandemic: Reported Cases and Deaths by Country, Territory, or Conveyance [internet]. 2020 [acesso em 2020 maio 9]. Disponível em: https://www.worldometers.info/ coronavirus/.

12. Brasil. Ministério da Saúde, Secretaria de Vigilância em Saúde. Boletim Epidemiológico especial - 06. COE-COVID19 [internet]. 2020. [acesso em 2020 maio 29]. Disponível em: https://portalarquivos. saude.gov.br/images/pdf/2020/April/03/BE6-Boletim-Especial-do-COE.pdf.

13. Reis AAC, Sóter APM, Furtado LAC, et al. Tudo a temer: financiamento, relação público e privado e o futuro do SUS. Saúde debate [internet]. 2016 [acesso em 2020 maio 28]; 40(esp):122-135. Disponível em: https://www.scielo.br/pdf/sdeb/v40nspe/01031104-sdeb-40-spe-0122.pdf.

14. Malta DC, Stopa SR, Pereira CA, et al. Cobertura de Planos de Saúde na população brasileira, segundo a Pesquisa Nacional de Saúde, 2013. Ciênc. Saúde Colet. 2017 [acesso em 2020 maio 28]; 22(1):179190. Disponível em: https://www.scielo.br/pdf/csc/ v22n1/1413-8123-csc-22-01-0179.pdf. 
15. Stopa SR, Malta DC, Monteiro CN, et al. Acesso e uso de serviços de saúde pela população brasileira, Pesquisa Nacional de Saúde 2013. Rev Saúde Pública. $2017 ; 51$ (supl1):3s.

16. Macinko J, Harris MJ. Brazil's family health strategy-delivering community-based primary care in a universal health system. N Engl J Med. 2015; $372(23): 2177-81$

17. Gudbjartsson DDF, Helgason A, Jonsson H, et al. Early Spread of SARS-Cov-2 in the Icelandic Population. MedRxiv [internet]. 2020 [acesso em 2020 maio 28]. Disponível em: https://doi.org/10.1101/2

020.03 .26 .20044446

18. Universidade Federal de Pelotas. Epidemiologia da COVID-19 no Rio Grande do Sul. Estudo de base populacional [internet]. [acesso em 2020 jun 27]. Disponível em: https://wp.ufpel.edu.br/covid19/ files/2020/05/Coletiva-Fase-4-20200526.pdf.

Recebido em 30/06/2020

Aprovado em 03/09/2020

Conflito de interesses: inexistente

Suporte financeiro: Fundação Parque Tecnológico de Santos 